\title{
MÉTODOS PARA AVALIAR A QUALIDADE FISIOLÓGICA DE SEMENTES DE ARROZ
}

\author{
N.L. DE MENEZES; T.L.D. DA SILVEIRA \\ Departamento de Fitotecnia - UFSM - CEP: 97119-900 - Santa Maria, RS.
}

\begin{abstract}
RESUMO: Com o objetivo de avaliar a eficiência de diferentes métodos para a determinação da qualidade fisiológica de sementes de arroz, foram utilizados dois grupos de dez lotes de sementes, das variedades BR-IRGA 409 e BR-IRGA 410. A qualidade dos lotes fó determinada através do teor de água, peso de mil sementes, teste de germinação e dos testes de vigor: primeira contagem de germinaçāo, classificaçăo do vigor de plântulas, envelhecimento acelerado, teste de frio modificado, tamanho e massa seca de plântulas e emergêncla no campo. Concluiu-se que os testes de frio modificado e classificação do vigor de plântulas são capazes de estratificar diferentes lotes de arroz pelo vigor e se correlacionam positivamente com a emergência no campo. O teste de envelhecimento acelerado, sob as condị̧̧̃es de $42^{\circ} \mathrm{C}$ e $100 \%$ de umidade relativa do ar, durante 120 horas, estratifica lotes de arroz, em função do vigor das sementes. Os testes de tamanho e massa seca de plântulas, quando eliminam as plântulas anormais e sementes nāo germinadas, não são capazes de estratificar lotes de sementes de arroz, em funçăo do vigor.

Descritores: Oryza sativa, germinaçao, testes de vigor.
\end{abstract}

\section{METHODS TO EVALUATE PHYSIOLOGICAL QUALITY OF RICE SEEDS.}

\begin{abstract}
Aiming to evaluate the efficiency of different methods to determine the physiological quality of rice seeds, two groups of 10 lots each of the varieties BR-IRGA 409 and BR-IRGA 410 were used. Seed quality was determined through seed water content, weight of 1,000 seeds, germination and vigor tests: first germination counting, classification of seedling vigor, accelerated aging, modiffed cold test, seedling growth and weight and field emergence. It was concluded that the modified cold test and classification of seedling vigor are capable of stratifying different rice samples according to their vigor and are positively correlated with field emergence. The accelerated aging, under $42^{\circ} \mathrm{C}$ and $100 \%$ relative humidity of alr conditions stratifies the samples in relation to seed vigor. The tests of seedling growth and weight, when eliminating abnormal seedlings and non-germinated seeds, are not capable of stratifying rice seed samples as a function of seed vigor.
\end{abstract}

Key words: Oriza sativa, germination, vigor tests.

\section{INTRODUÇÃO}

A demanda por sementes de arroz de alto padrão de qualidade é crescente e deverá se intensificar com o advento do livre comércio entre paises integrantes do MERCOSUL, assim exigindo tecnologia moderna, eficiente e dinâmica dentro da indústria de sementes que resulta num controle de qualidade cada vez mais efetivo. Por isso, a avaliação da qualidade fisiológica das sementes é um instrumento fundamental e de grande valia em um programa de produção de arroz, pois o esclarecimento dos efeitos, dos diversos fatores que afetam a qualidade das sementes, depende da eficiência dos métodos utilizados para determiná-la. $O$ emprego de metodologia adequada, além de fornecer informaçŏes a respeito da viabilidade das sementes, possibilita estimar o comportamento durante $o$ armazenamento, o desempenho no campo e decidir sobre o descarte de lotes de sementes de baixa qualidade, diminuindo, assim, os riscos de prejuizos.
A qualidade fisiológica é, rotineiramente, avaliada pelo teste padrão de germinação, que supre condiç̋̃es favoráveis, de umidade e temperatura, permitindo expressar o potencial máximo de um lote em produzir plântulas normais. Entretanto, esse teste pode ser pouco eficiente para indicar o desempenho no campo, onde as condiç̃es nem sempre são ideais (ISELY, 1957). Em função disto, desenvolveu-se o conceito de vigor e, consequentemente, diversos testes têm sido propostos para avaliar de forma mais precisa a qualidade fisiológica (MCDONALD JUNIOR, 1975), dentre eles, alguns são de fácil execução, baixo custo e rápidos, embora nem sempre completamente padronizados em suas metodologias.

$O$ vigor das sementes pode ser entendido como o nível de energia que elas dispõem para realizarem as tarefas do processo germinativo (CARVALHO, 1986); seu efeito, no desempenho das sementes, manifesta-se de diferentes formas no campo e no armazenamento (GRABE, 1976). 
No caso especifico do arroz, vários são os testes utilizados para avaliar o vigor das sementes, tais como primeira contagem de germinação, envelhecimento acelerado, classificação do vigor de plântulas, peso e crescimento de plântula, velocidade de emergência, imersão em água quente, entre outros.

Atualmente, há uma tendência de se estabelecer relações entre as informações obtidas nos diversos métodos, que avaliam a qualidade fisiológica das sementes e a emergência no campo. Entretanto, há grande dificuldade para se estimar a emergência no campo, devido a falta de padronização de procedimentos e de parâmetros avaliados, o que impede uma uniformidade de resultados (BARROS, 1988). Isto recomenda a obtenção do maior número de informações, que permitam identificar os lotes com maiores possibilidades de apresentar um bom desempenho no campo (MARCOS FILHO et al., $1984 ; 1987)$. Estes fatos evidenciam a necessidade de estudos sobre os métodos que avaliam a qualidade fisiológica das sementes de arroz e que permitam identificar o potencial das sementes.

O presente trabalho foi desenvolvido com os objetivos de avaliar a eficiência de diferentes métodos utilizados para a determinação da qualidade fisiológica de sementes de arroz, procurando obter informações que possam indicar opções nos programas de controle de qualidade, bem como tornar possivel, através de testes de laboratório, a identificação de potenciais de emergência no campo

\section{MATERIAL E MÉTODOS}

O trabalho foi desenvolvido no Laboratório de Análise de Sementes de Produção(LASP) e no campo experimental do Departamento de Fitotecnia, da Universidade Federal de Santa Maria(UFSM), no ano de 1992.

Foram utilizados dois grupos de dez lotes, das variedades BR-IRGA 409 e BR-IRGA 410, perfazendo 20 lotes de arroz, que apresentavam características fisiológicas diferentes, tendo sido selecionados dentre aqueles recebidos pelo LASP. UFSM, baseando-se nos resultados iniciais de germinação e safra agricola da produção das sementes.

As características, fisica e fisiológica, dos lotes foram determinadas através do teor de água, peso de mil sementes, teste de germinação e dos testes de vigor: primeira contagem de germinação, classificação do vigor de plântulas, envelhecimento acelerado, teste de frio modificado, tamanho de plântulas (tamanho de raiz e parte aérea), massa seca de plântula (raiz e parte aérea) e emergência no campo.
O teor de água e o peso de mil sementes foram determinados de acordo com as Regras para Análise de Sementes (BRASIL, 1992). Sendo, o primeiro pelo método de estufa, a $105^{\circ} \mathrm{C} \pm 3^{\circ} \mathrm{C}$, durante 24 horas, utilizando-se duas amostras por lote e o segundo, a partir de oito repetições de 100 sementes, obtidas da porção sementes puras.

$O$ teste de germinação foi conduzido de acordo com as Regras para Análise de Sementes (BRASIL, 1992), usando-se quatro repetições de 100 sementes para cada lote, em germinador regulado a $25^{\circ} \mathrm{C}$, durante todo o periodo do teste. O volume de água, para a embebição das sementes, foi o equivalente a 2,5 vezes o peso do papel substrato. As contagens foram realizadas aos 5 e 14 dias, após a semeadura.

$O$ teste de primeira contagem de germinação foi realizado juntamente com o teste anterior e constou do registro da porcentagem de plântulas normais, verificadas no quinto dia após a instalação do teste.

O teste de classificação do vigor de plântulas foi instalado do mesmo modo que o teste de germinação, repetindo-se o substrato, quantidade de água e a temperatura. Entretanto, no momento das contagens, foram registradas as plântulas normais fortes, médias e fracas, seguindo a descrição feita por MARCOS FLHO et al. (1987).

$O$ teste de envelhecimento acelerado foi realizado utilizando-se $\mathbf{4 0 0}$ sementes por lote, em caixas plásticas do tipo "gerbox", as quais funcionaram como mini-câmaras, conforme metodologia proposta pelo Comite de Vigor da Association of Official Seed Analysis - AOSA e descrito por MARCOS FILHO et al. (1987). As sementes permaneceram no germinador sob as condições de $42^{\circ} \mathrm{C}$ e $100 \%$ de umidade relativa do ar, durante 120 horas. Após esse período, as sementes foram colocadas para germinar, de acordo com as recomendações do teste padrão de germinação. A interpretação do teste foi efetuada aos dez dias após a semeadura, computando-se a porcentagem de plântulas normais por amostra e obtendo-se dados médios para cada lote.

Para o teste de tamanho de plântulas, usou-se quatro repetições de dez sementes, as quais foram distribuidas em papel toalha, sobre uma linha reta traçada no sentido longitudinal, localizada no terço superior do substrato umedecido. Em segui$\mathrm{da}$, os rolos formados com o substrato contendo as sementes foram colocados em um germinador, sob a temperatura constante, de $25^{\circ} \mathrm{C}$. Após dez dias se determinou o comprimento médio das plântulas normais e de suas partes (raiz e parte aérea). Posteriormente, foi determinado, a massa seca das mesmas plântulas, secadas em estufa a $70^{\circ} \mathrm{C}$, por 48 horas. 
$O$ teste de frio modificado foi conduzido com quatro repetiçóes de $\mathbf{5 0}$ sementes por lote, semeadas em rolos de papel toalha, marca Germitest. Os rolos foram cobertos com sacos plásticos, para evitar a perda de umidade, e mantidos em geladeira com temperatura de $10^{\circ} \mathrm{C}$, durante sete dias. Vencido este periodo os rolos foram transferidos para um germinador a $25^{\circ} \mathrm{C}$, onde permaneceram por mais sete dias. A interpretação do teste foi realizada computando-se as porcentagens de plântulas normais por repetição.

No teste de emergência no campo, utilizou-se $\mathbf{4 0 0}$ sementes por lote, semeadas em linhas distanciadas de $30 \mathrm{~cm}$, a uma profundidade de $3 \mathrm{~cm}$. Decorridos 15 dias, após a instalação do teste, foi realizada a contagem das plântulas estabelecidas em cada linha.

O delineamento estatístico adotado foi inteiramente casualizado, exceto para a emergência no campo, para o qual se utilizou blocos ao acaso, com quatro repetiçбes. As comparaçøes entre as médias, de todos os parâmetros analisados, foram efetuadas através do teste de Tukey, ao nivel de 5\% de probabilidade.

\section{RESULTADOS E DISCUSSÃO}

Os valores médios, relativos ao grau de umidade inicial $c o$ peso de mil sementes estão apresentados na TABELA 1. Esses dados não foram analisados estatisticamente, servindo apenas para caracterização inicial dos lotes. O grau de umidade inicial variou de $12,9 \%$ a $13,8 \%$, entre os lotes da variedade $B R$-IRGA 409 e $12,7 \%$ a $13,8 \%$, entre os lotes da variedade BR-IRGA 410 , niveis estes compativeis com o armazenamento de sementes de arroz e por isto, não responsáveis pelas variações observadas na qualidade dos lotes de sementes.

TABELA 1. Grau de umidade e Peso de mil sementes dos 20 lotes de sementes de arroz, das variedades BRIRGA 409(A) e BR-IRGA 410(B), antes da realização dos testes.

\begin{tabular}{ccccc}
\hline \multirow{2}{*}{ Lotes } & \multicolumn{2}{c}{ Grau de Umidade (\%) } & \multicolumn{2}{c}{ Peso de Mil Sementes (g) } \\
& A & B & A & B \\
\hline 1 & 13,4 & 12,8 & 23,75 & 27,40 \\
2 & 13,4 & 12,7 & 24,80 & 24,77 \\
3 & 13,2 & 13,3 & 24,35 & 26,13 \\
4 & 13,1 & 13,6 & 24,65 & 25,72 \\
5 & 13,4 & 13,4 & 25,55 & 26,61 \\
6 & 13,1 & 13,8 & 24,07 & 24,86 \\
7 & 13,3 & 13,2 & 24,76 & 24,70 \\
8 & 13,5 & 13,2 & 26,71 & 25,02 \\
9 & 12,9 & 13,1 & 24,88 & 25,20 \\
10 & 13,8 & 13,8 & 24,42 & 27,52 \\
\hline Média & - & - & 24,79 & 25,70 \\
\hline \hline
\end{tabular}

$O$ peso médio de mil sementes da variedade BRIRGA 410 foi superior ao peso da variedade BR. IRGA 409, sendo, respectivamente, $25,70 \mathrm{~g}$ e $24,79 \mathrm{~g}$, coincidindo com a observação visual do maior tamanho para a variedade BR-IRGA 410.

Na TABELA 2, são apresentados os resultados relativos a germinação, onde se observa que, considerando os valores médios dos lotes, a variedade BR-IRGA 410 apresentou germinação superior a variedade BR-IRGA 409. As variaçōes no comportamento dos lotes, nas duas variedades, refletiram a qualidade das suas sementes. Os lotes com menor qualidade inicial, determinada na fase de seleção, apresentaram menor porcentagem de germinação.
Desta forma, o teste de germinação tornou-se o parâmetro referencial para a determinação da qualidade dos lotes de arroz, sendo capaz de indicar a tendência do vigor e da emergência no campo, confirmando o desempenho esperado, quando os lotes apresentam qualidade inicial distinta.

A TABELA 3 contém os resultados relativos ao teste de primeira contagem de germinação. Para a variedade BR-IRGA 409, o lote 8 apresentou maior vigor, pois teve o maior número de plântulas normais no quinto dia após a instalação do teste. Os lotes 9 e 5 apresentaram desempenho semelhantes, na primeira contagem de germinação, embora tenham diferido no teste anterior. 
TABELA 2. Resultados médios relativos a porcentagem de germinação(\%), de 20 lotes de sementes de arroz, das variedades BR-IRGA 409 e BR-IRGA 410. Santa Maria - RS.1992.

\begin{tabular}{cccc}
\hline \hline Lotes & BR-IRGA 409 & Lotes & BR-IRGA 410 \\
\hline 9 & $90,00 \mathrm{a}^{*}$ & 8 & $93,50 \mathrm{a}$ \\
4 & $88,50 \mathrm{ab}$ & 3 & $93,00 \mathrm{a}$ \\
2 & $84,25 \mathrm{ab}$ & 10 & $90,50 \mathrm{ab}$ \\
8 & $83,00 \mathrm{ab}$ & 1 & $83,25 \mathrm{bc}$ \\
3 & $80,75 \mathrm{bc}$ & 7 & $83,25 \mathrm{bc}$ \\
7 & $79,25 \mathrm{bcd}$ & 5 & $79,75 \mathrm{c}$ \\
6 & $71,25 \mathrm{cde}$ & 4 & $75,75 \mathrm{~cd}$ \\
10 & $69,25 \mathrm{de}$ & 6 & $74,75 \mathrm{~cd}$ \\
5 & $67,25 \mathrm{e}$ & 2 & $67,00 \mathrm{de}$ \\
1 & $37,50 \mathrm{f}$ & 9 & $59,25 \mathrm{e}$ \\
\hline Média & $75,10 \mathrm{~B}$ & $80,00 \mathrm{~A}$ \\
C.V.(\%) & 4,54 & & 4,54 \\
\hline \hline
\end{tabular}

* Médias seguidas por diferentes letras minúsculas (colunas) e maiúsculas (linhas) diferem entre si pelo teste de Tukey a $5 \%$ de probabilidade.

TABELA 3. Resultados médios relativos a porcentagem de plântulas normais obtidas no teste de Primeira Contagem de germinação(\%), em 20 lotes de sementes de arroz, das variedades BR-IRGA 409 e BR-IRGA 410. Santa Maria - RS.1992.

\begin{tabular}{cccc}
\hline Lotes & BR-IRGA 409 & Lotes & BR-IRGA 410 \\
\hline 8 & $52,50 \mathrm{a}^{*}$ & 1 & $47,00 \mathrm{a}$ \\
9 & $38,00 \mathrm{~b}$ & 5 & $41,00 \mathrm{ab}$ \\
5 & $30,75 \mathrm{bc}$ & 10 & $40,25 \mathrm{abc}$ \\
3 & $25,00 \mathrm{c}$ & 3 & $37,25 \mathrm{abcd}$ \\
4 & $22,75 \mathrm{~cd}$ & 2 & $33,25 \mathrm{bcde}$ \\
7 & $21,75 \mathrm{~cd}$ & 7 & $29,75 \mathrm{cde}$ \\
6 & $15,00 \mathrm{de}$ & 4 & $28,25 \mathrm{def}$ \\
2 & $15,00 \mathrm{de}$ & 8 & $23,75 \mathrm{ef}$ \\
1 & $9,75 \mathrm{e}$ & 6 & $20,50 \mathrm{f}$ \\
10 & $7,00 \mathrm{f}$ & 9 & $4,75 \mathrm{~g}$ \\
\hline Média & $23,75 \mathrm{~B}$ & & $30,58 \mathrm{~A}$ \\
C.V.(\%) & 8,19 & & 8,19 \\
\hline \hline
\end{tabular}

* Médias seguidas por diferentes letras minúsculas (colunas) e maiúsculas (linhas) diferem entre si pelo teste de Tukey a 5\% de probabilidade.

A maior quantidade de plântulas normais no quinto dia não determinou a maior germinação final, pois o vigor individual das sementes pode manifestar-se de modo variável, nos lotes de qualidade baixa ou intermediária, assim como, o período de duração do teste de germinação, favorece a expressão do potencial máximo, mesmo para aquelas sementes que tenham menor vigor. $O$ lote 10 teve $o$ menor desempenho na primeira contagem de germinação, diferindo significativamente dos demais.
Para a variedade BR IRGA-410, observou-se diferenças significativas na qualidade dos lotes, através da formação de grupos com desempenho semelhantes, onde o lote 1 apresentou o maior vigor sem diferir dos lotes 5,10 e 3 . O lote 9 teve o menor vigor. Nesta variedade, o lote mais vigoroso apresentou comportamento intermediário no teste de germinação, porém o de menor vigor confirmou a baixa qualidade observada no teste de germinação. 
TABELA 4. Resultados médios obtidos pelo Teste de Frio Modificado(\%), em 20 lotes de arroz, das variedades BR-IRGA 409 e BR-IRGA 410. Santa Maria - RS. 1992.

\begin{tabular}{clcc}
\hline \hline Lotes & BR-IRGA 409 & Lotes & BR-IRGA 410 \\
\hline 9 & $87,00 \mathrm{a}^{*}$ & 8 & $83,50 \mathrm{a}$ \\
4 & $84,50 \mathrm{a}$ & 3 & $82,50 \mathrm{a}$ \\
7 & $81,00 \mathrm{ab}$ & 10 & $80,00 \mathrm{ab}$ \\
2 & $79,00 \mathrm{abc}$ & 7 & $78,75 \mathrm{abc}$ \\
8 & $77,75 \mathrm{abc}$ & 1 & $76,25 \mathrm{abcd}$ \\
3 & $77,75 \mathrm{abc}$ & 6 & $70,25 \mathrm{bcde}$ \\
10 & $72,00 \mathrm{bcd}$ & 5 & $67,75 \mathrm{cdef}$ \\
6 & $68,25 \mathrm{~cd}$ & 4 & $66,75 \mathrm{def}$ \\
5 & $61,00 \mathrm{~d}$ & 9 & 60,00 ef \\
1 & $36,75 \mathrm{e}$ & 2 & $57,25 \mathrm{f}$ \\
\hline Média & $72,50 \mathrm{~A}$ & & $72,30 \mathrm{~A}$ \\
C.V.(\%) & 4,88 & 4,88 \\
\hline \hline
\end{tabular}

* Médias seguidas por diferentes letras minúsculas (colunas) e maiúsculas (linhas) diferem entre si pelo teste de Tukey a $5 \%$ de probabilidade.

TABELA 5. Resultados médios obtidos pelo Teste de Envelhecimento Acelerado(\%) em 20 lotes de arroz, das variedades BR-IRGA 409 e BR-IRGA 410. Santa Maria - RS. 1992.

\begin{tabular}{cccc}
\hline \hline Lotes & BR-IRGA 409 & Lotes & BR-IRGA 410 \\
\hline 9 & $77,00 \mathrm{a}^{*}$ & 8 & $79,75 \mathrm{a}$ \\
2 & $74,75 \mathrm{a}$ & 7 & $76,75 \mathrm{a}$ \\
4 & $70,75 \mathrm{ab}$ & 10 & $73,00 \mathrm{a}$ \\
7 & $70,50 \mathrm{ab}$ & 5 & $55,50 \mathrm{~b}$ \\
10 & $61,50 \mathrm{bc}$ & 3 & $49,75 \mathrm{~b}$ \\
8 & $50,25 \mathrm{c}$ & 6 & $31,00 \mathrm{c}$ \\
5 & $36,25 \mathrm{~d}$ & 4 & $29,00 \mathrm{c}$ \\
6 & $23,25 \mathrm{e}$ & 9 & $27,00 \mathrm{c}$ \\
3 & $22,25 \mathrm{e}$ & 1 & $24,50 \mathrm{c}$ \\
1 & $18,00 \mathrm{e}$ & 2 & $22,00 \mathrm{c}$ \\
\hline Média & $50,45 \mathrm{~A}$ & & $46,83 \mathrm{~B}$ \\
C.V.(\%) & 5,92 & & 5,92 \\
\hline \hline
\end{tabular}

- Médias seguidas por diferentes letras minúsculas (colunas) e maiúsculas (linhas) diferem entre si pelo teste de Tukey a $5 \%$ de probabilidade.

Na TABELA 4 são apresentados os resultados do teste de frio modificado, onde se verifica diferenças entre os lotes nos grupos das duas variedades. Os resultados do teste, porém, por serem próximos aos obtidos no teste de germinação, indicam que o efeito da combinação de baixas temperaturas e alta umidade não foi muito drástico e os lotes testados tinham capacidade para germinar sob amplas variações de conteúdo de água e temperatu$r a$, como preveem MARCOS FILHO et al. (1987) para tais situaçбes. Vários lotes não diferiram entre si, sugerindo baixa sensibilidade do teste para estratificacăo do vigor, entre lotes de qualidade aproximada, no entanto, foi possivel identificar lotes que apresentavam grandes diferenças entre si, em funç̃o do vigor das sementes. 
Os resultados relativos ao teste de envethecimento acelerado, apresentados na TABELA 5, permitem observar a estratificação dos lotes, dentro de cada grupo de varietal. Constatou-se, tambem, que os resultados deste teste revelaram semelhanças com o teste de germinação, visto que, para a variedade BR-IRGA 409, os lotes 9, 2 e 4 apresentaram os melhores resultados e o lote 1 o menor resultado, como no teste de germinação. O mesmo ocorreu com a variedade BR-IRGA 410, onde o lote 8 foi o de melhor desempenho e os lotes 2 e 9, que não diferiram entre si, tiveram as menores porcen- tagens, nos dois testes. Os resultados do teste de envelhecimento indicaram que as condiçбes de estresse estabelecidas para o teste foram suficientes para estratificar o vigor dos lotes, embora estes resultados discordem daqueles obtidos por WETZEL (1972), onde os periodos de até 120 horas de envethecimento não afetaram a germinação das sementes de arroz, das safras 1970/1971, de modo que indicassem possiveis diferenças entre variedades.

No estudo em discussão, $o$ uso de caixas do tipo gerbox, como mini-câmaras e as variedades modernas BR-IRGA 409 e BR-IRGA 410

TABELA 6. Resultados médios obtidos pelo Teste de Classificação do Vigor(\%), aplicado em 20 lotes de sementes de arroz, das variedades BR-IRGA 409 e BR-IRGA 410. Santa Maria - RS. 1992.

\begin{tabular}{|c|c|c|c|c|c|}
\hline \multicolumn{2}{|c|}{ Vigor Forte } & \multicolumn{2}{|c|}{$\begin{array}{l}\text { - BR-IRGA } 40 \\
\text { Vigor Médio }\end{array}$} & \multicolumn{2}{|c|}{ Vigor Fraco } \\
\hline $\begin{array}{c}\text { Lot } \\
4 \\
9 \\
8 \\
2 \\
3 \\
7 \\
5 \\
6 \\
10 \\
1\end{array}$ & $\begin{array}{l}\% \\
80,25 \mathrm{a} \\
79,50 \mathrm{ab} \\
78,75 \mathrm{ab} \\
73,25 \mathrm{ab} \\
71,50 \mathrm{ab} \\
69,00 \mathrm{bc} \\
60,25 \mathrm{~cd} \\
59,50 \mathrm{~cd} \\
54,25 \mathrm{~d} \\
28,75 \mathrm{c}\end{array}$ & $\begin{array}{c}\text { Lote } \\
10 \\
6 \\
2 \\
9 \\
7 \\
3 \\
1 \\
4 \\
5 \\
8\end{array}$ & $\begin{array}{c}\% \\
15,00 \mathrm{a} \\
11,75 \mathrm{ab} \\
11,00 \mathrm{ab} \\
10,50 \mathrm{ab} \\
10,25 \mathrm{ab} \\
9,25 \mathrm{ab} \\
8,75 \mathrm{ab} \\
8,50 \mathrm{ab} \\
7,00 \mathrm{ab} \\
4,25 \mathrm{~b}\end{array}$ & $\begin{array}{c}\text { Lote } \\
1 \\
7 \\
3 \\
6 \\
10 \\
8 \\
2 \\
9 \\
4 \\
5\end{array}$ & $\begin{array}{c}\% \\
11,00 \mathrm{a} \\
7,50 \mathrm{ab} \\
5,50 \mathrm{ab} \\
5,50 \mathrm{ab} \\
5,25 \mathrm{ab} \\
4,25 \mathrm{ab} \\
4,00 \mathrm{~b} \\
4,00 \mathrm{~b} \\
3,75 \mathrm{~b} \\
2,50 \mathrm{~b}\end{array}$ \\
\hline $\begin{array}{l}\text { Média } \\
\text { C.V.(\%) }\end{array}$ & $\begin{array}{c}65,50 \mathrm{~B} \\
6) \\
6,03\end{array}$ & & $\begin{array}{l}9,63 \mathrm{~A} \\
35,70\end{array}$ & & $\begin{array}{c}5,33 \mathrm{~A} \\
46,86\end{array}$ \\
\hline \multicolumn{2}{|c|}{ Vigor Forte } & \multicolumn{2}{|c|}{$\begin{array}{c}\text { - BR-IRGA } 4 \\
\text { Vigor Médio }\end{array}$} & \multicolumn{2}{|c|}{ Vigor Fraco } \\
\hline $\begin{array}{c}\text { Lote } \\
3 \\
10 \\
8 \\
7 \\
1 \\
5 \\
6 \\
4 \\
2 \\
9\end{array}$ & $\begin{array}{c}\% \\
83,75 \mathrm{a} \\
82,75 \mathrm{a} \\
82,50 \mathrm{a} \\
76,50 \mathrm{a} \\
75,75 \mathrm{a} \\
74,00 \mathrm{ab} \\
64,50 \mathrm{bc} \\
63,00 \mathrm{c} \\
60,25 \mathrm{c} \\
39,00 \mathrm{~d}\end{array}$ & $\begin{array}{c}\text { Lote } \\
9 \\
4 \\
8 \\
6 \\
3 \\
10 \\
1 \\
7 \\
2 \\
5\end{array}$ & $\begin{array}{l}\% \\
20,25 \mathrm{a} \\
13,75 \mathrm{ab} \\
11,00 \mathrm{ab} \\
10,25 \mathrm{ab} \\
9,25 \mathrm{ab} \\
7,75 \mathrm{ab} \\
7,50 \mathrm{ab} \\
6,75 \mathrm{ab} \\
6,75 \mathrm{ab} \\
5,75 \mathrm{~b}\end{array}$ & $\begin{array}{c}\text { Lote } \\
9 \\
4 \\
2 \\
1 \\
7 \\
6 \\
10 \\
8 \\
5 \\
3\end{array}$ & $\begin{array}{l}\% \\
9,75 \mathrm{a} \\
8,75 \mathrm{ab} \\
8,00 \mathrm{ab} \\
7,25 \mathrm{ab} \\
6,00 \mathrm{ab} \\
5,50 \mathrm{ab} \\
4,75 \mathrm{~b} \\
3,50 \mathrm{~b} \\
3,25 \mathrm{~b} \\
2,75 \mathrm{~b}\end{array}$ \\
\hline $\begin{array}{l}\text { Média } \\
\text { C.V.(\%) }\end{array}$ & $\begin{array}{l}70,20 \mathrm{~A} \\
6,03\end{array}$ & & $\begin{array}{l}9,90 \mathrm{~A} \\
35,70\end{array}$ & & $\begin{array}{c}5,95 \mathrm{~A} \\
46,86\end{array}$ \\
\hline
\end{tabular}

- Medias seguidas por diferentes letras minúsculas e maiúsculas nas colunas diferem entre si pelo teste de Tukey a 5\% de probabilidade. 
constituiram-se em fatores decisivos no estabelecimento de diferenças entre os resultados deste ensaio e os obtidos por WETZEL (1972).

Mais recentemente, o teste de envelhecimento acelerado tem se mostrado eficiente, em diversas culturas, como apontaram COSTA et al. (1984) em soja, FRATIN (1987) em milho, DIAS \& BARROS (1992) em feijão, ratificando o seu uso como teste de vigor.

Os resultados relativos ao teste de classificação do vigor são apresentados na TABELA 6. As porcentagens de vigor médio e vigor fraco não conseguiram estratificar de forma adequada os lotes, nem acrescentaram informações que pudessem ser utilizadas para separar os lotes das duas variedades de arroz. O vigor forte, no entanto, estratificou os lotes, porque os mais vigorosos apresentam maior quantidade de plântulas fortes.

Nas TABELAS 7 e 8 são apresentados os resultados relativos ao tamanho médio e massa seca de plântula, subdivididos em parte aérea e raiz. Observou-se que estes parâmetros não se prestaram para avaliar o vigor dos lotes, porque não detectaram as diferenças existentes entre os mesmos. Estes resultados discordam daqueles observados por DAN et al. (1987), para as sementes de soja, quando os autores consideraram a massa seca e o tamanho de plântula, parâmetros sensiveis para expressar o vigor de lotes de sementes. As condiçóes oferecidas no teste foram favoráveis e as partes das plântulas normais avaliadas tiveram crescimento rápido, uniforme e tamanhos pouco discrepantes, mesmo para aqueles lotes com menor número de sementes germinadas.

Os resultados relativos a emergência dos 20 lotes de sementes de arroz, no campo, estão apresentados na TABELA 9. A emergência das plântulas no campo seguiu a tendência estabelecida pelos testes de germinação e vigor. Os lotes identificados como de alta ou baixa qualidades, determinadas em condições favoráveis no laboratório, tiveram comportamento no campo de acordo com aquela classificação. O teste de emergência no campo foi realizado na época normal de semeadura para o arroz, no RS. Tal fato contribuiu para que se obtivesse temperatura e umidade necessárias e suficientes para uma boa germinação das sementes no campo. Assim, a emergência foi semelhante e até superior em alguns lotes, à germinação obtida no LASP-UFSM

Os valores dos coeficientes de correlação linear encontrados para todas combinações entre os métodos encontram-se na TABELA 10, onde se verifica a existência de correlação positiva e altamente significativa entre os dados de germinação, primeira contagem, frio modificado, envelhecimento acelerado, classificação do vigor e emergência no campo, combinados entre si.

No presente trabalho, as correlações entre os testes de germinação e de vigor foram consideradas importantes quando seus valores

TABELA 7. Resultados obtidos nos testes de Tamanho Médio e Massa Seca de Plântulas (parte aérea e raiz), em 20 lotes de sementes de arroz, da variedade BR-IRGA 409. Santa Maria, RS. 1992.

\begin{tabular}{|c|c|c|c|c|c|c|c|c|}
\hline & \multicolumn{4}{|c|}{ Tamanho Médio de Plântulas(cm) } & \multicolumn{4}{|c|}{ Massa Seca de Plântulas(mg/pl) } \\
\hline & \multicolumn{2}{|c|}{ Parte Aérea } & \multicolumn{2}{|c|}{ Raiz } & \multicolumn{2}{|c|}{ Parte Aérea } & \multicolumn{2}{|c|}{ Raiz } \\
\hline & Lote & Média & Lote & e Média & Lote & Média & Lote & Média \\
\hline & 81 & $10,60 \mathrm{a}^{*}$ & & $16,70 \mathrm{a}$ & 9 & $5,88 \mathrm{a}$ & 5 & $2,77 \mathrm{a}$ \\
\hline & 11 & $10,35 \mathrm{ab}$ & 4 & $16,68 \mathrm{a}$ & 8 & $5,86 \mathrm{a}$ & 2 & $2,66 \mathrm{a}$ \\
\hline & 31 & $10,32 \mathrm{ab}$ & 3 & $16,26 \mathrm{a}$ & 4 & $5,73 \mathrm{a}$ & 9 & $2,60 \mathrm{a}$ \\
\hline & 6 & $9,89 \mathrm{ab}$ & 10 & 16,10 a & 6 & $5,71 \mathrm{a}$ & 6 & $2,54 \mathrm{a}$ \\
\hline & 4 & $9,87 \mathrm{ab}$ & 8 & 16,09 a & 5 & $5,69 \mathrm{a}$ & 10 & $2,52 \mathrm{a}$ \\
\hline & 2 & $9,61 \mathrm{ab}$ & 9 & $16,08 \mathrm{a}$ & 10 & $5,63 \mathrm{a}$ & 4 & $2,49 \mathrm{a}$ \\
\hline & 9 & $9,52 \mathrm{ab}$ & 6 & $16,00 \mathrm{a}$ & 2 & $5,60 \mathrm{a}$ & 7 & $2,48 \mathrm{a}$ \\
\hline & 5 & $9,22 \mathrm{ab}$ & 5 & $15,88 \mathrm{a}$ & 7 & $5,53 \mathrm{a}$ & 8 & $2,43 \mathrm{a}$ \\
\hline & 7 & $9,17 \mathrm{ab}$ & 7 & $15,74 \mathrm{a}$ & 3 & $5,52 \mathrm{a}$ & 3 & $2,32 \mathrm{a}$ \\
\hline & 10 & $9,01 \mathrm{~b}$ & 1 & 14,81 a & 1 & $5,37 \mathrm{a}$ & 1 & $2,20 \mathrm{a}$ \\
\hline Média & & 9,75 & & 16,03 & & 5,65 & & 2,59 \\
\hline CV(\%) & & 6,29 & & 4,94 & & 7,31 & & 10,74 \\
\hline
\end{tabular}

* Médias seguidas por diferentes letras minúsculas nas colunas diferem entre si pelo teste de Tukey a $5 \%$ de probabilidade. 
TABELA 9. Resultados médios obtidos no Teste de Emergência no campo(\%), para 20 lotes de sementes de arroz ,das variedades BR-IRGA 409 e BR-IRGA 410.Santa Maria - RS.1992.

\begin{tabular}{cccc}
\hline Lotes & BR-IRGA 409 & Lotes & BR-IRGA 410 \\
\hline 9 & $72,50 \mathrm{a}^{*}$ & 10 & $81,25 \mathrm{a}$ \\
7 & $68,75 \mathrm{ab}$ & 3 & $77,25 \mathrm{a}$ \\
3 & $68,00 \mathrm{ab}$ & 8 & $72,75 \mathrm{a}$ \\
8 & $67,50 \mathrm{ab}$ & 6 & $70,75 \mathrm{a}$ \\
6 & $65,00 \mathrm{ab}$ & 5 & $63,00 \mathrm{~b}$ \\
4 & $58,75 \mathrm{bc}$ & 7 & $61,25 \mathrm{~b}$ \\
2 & $55,25 \mathrm{bc}$ & 1 & $58,25 \mathrm{c}$ \\
10 & $50,25 \mathrm{c}$ & 2 & $54,00 \mathrm{~d}$ \\
5 & $42,50 \mathrm{~d}$ & 4 & $49,75 \mathrm{~d}$ \\
1 & $40,50 \mathrm{~d}$ & 9 & $47,00 \mathrm{e}$ \\
\hline Média & $58,87 \mathrm{~B}$ & & $63,52 \mathrm{~A}$ \\
C.V.(\%) & 6,09 & 6,09 \\
\hline \hline
\end{tabular}

* Médias seguidas por diferentes letras minúsculas (colunas) e maiúsculas (linhas) diferem entre si pelo teste de Tukey a $5 \%$ de probabilidade.

TABELA 8. Resultados obtidos nos Testes de Tamanho Médio e Massa Seca de Plântulas (Parte Aérea e Raiz), em 20 lotes de sementes de arroz da variedade BR-IRGA 410. Santa Maria, RS. 1992.

\begin{tabular}{|c|c|c|c|c|c|c|c|c|}
\hline & \multicolumn{4}{|c|}{ Tamanho de Plântulas(cm) } & \multicolumn{4}{|c|}{ Massa Seca de Plântulas(mg/pl) } \\
\hline & \multicolumn{2}{|c|}{ Parte Aérea } & \multicolumn{2}{|c|}{ Raiz } & \multicolumn{2}{|c|}{ Parte Aérea } & \multicolumn{2}{|r|}{ Raiz } \\
\hline & Lot & te Média & Lote & e Média & Lote & Média & Lote & Média \\
\hline & 5 & $9,79 a^{*}$ & 1 & $16,37 \mathrm{a}$ & 1 & $5,87 \mathrm{a}$ & 10 & $3,54 \mathrm{a}$ \\
\hline & 6 & $9,69 \mathrm{a}$ & 5 & $16,35 \mathrm{a}$ & 6 & 5,85 a & 5 & $2,77 \mathrm{~b}$ \\
\hline & & $9,51 \mathrm{ab}$ & 10 & $16,27 \mathrm{a}$ & 3 & $5,84 \mathrm{a}$ & 7 & $2,73 \mathrm{~b}$ \\
\hline & & $9,47 \mathrm{ab}$ & 2 & $16,19 \mathrm{a}$ & 5 & $5,80 \mathrm{a}$ & 9 & $2,72 \mathrm{~b}$ \\
\hline & 3 & $9,20 \mathrm{ab}$ & 7 & 16,11 a & 7 & $5,51 \mathrm{a}$ & 8 & $2,71 \mathrm{~b}$ \\
\hline & 7 & $9,07 \mathrm{abc}$ & 8 & $16,09 \mathrm{a}$ & 10 & $5,50 \mathrm{a}$ & 1 & $2,61 \mathrm{~b}$ \\
\hline & 9 & $8,62 \mathrm{abc}$ & 6 & 15,98 a & 2 & 5,31 a & 6 & $2,50 \mathrm{~b}$ \\
\hline & 4 & 8,62 abc & 9 & 15,93 a & 4 & $5,15 \mathrm{a}$ & 3 & 2,49 b \\
\hline & 10 & 8,12 bc & 4 & $15,86 \mathrm{a}$ & 9 & 5,15 a & 4 & 2,46 b \\
\hline & 8 & $7,65 \mathrm{c}$ & 3 & $15,81 \mathrm{a}$ & 8 & $4,99 \mathbf{a}$ & 2 & $2,34 \mathrm{~b}$ \\
\hline Média & & 8,94 & & 16,10 & & 5,49 & & 2,68 \\
\hline $\mathrm{CV}(\%)$ & & 6,29 & & 4,94 & & 7,31 & & 10,74 \\
\hline
\end{tabular}

* Média seguidas por diferentes letras minúsculas nas colunas diferem entre si pelo teste de Tukey a $5 \%$ de probabilidade. 


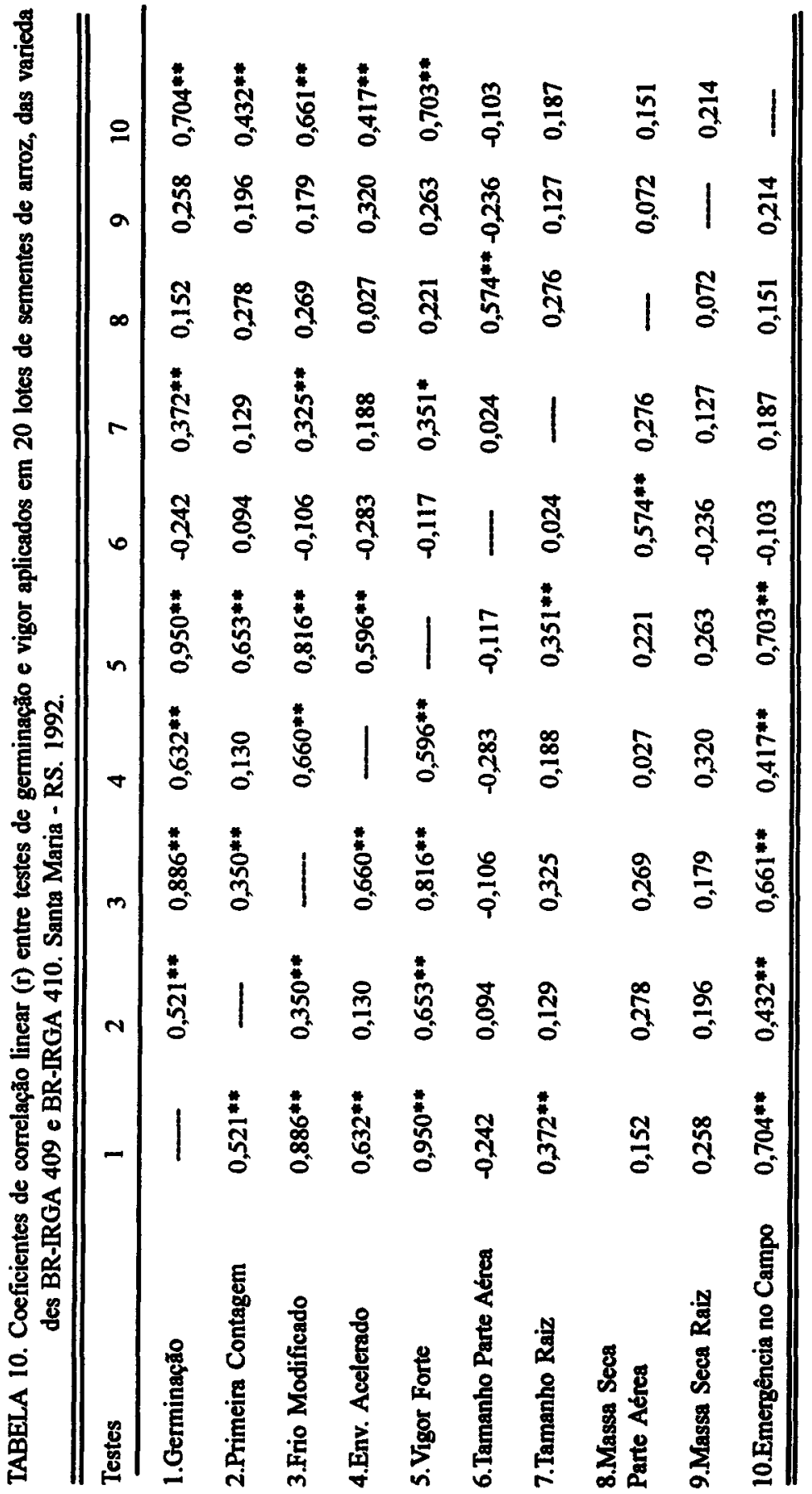


ram ou excederam o valor de 0,70 , visto que coeficientes de correlação simples com valores abaixo deste possibilitam interpretações errôneas.

Os resultados do teste de germinação, frio modificado, plântulas fortes na classificação do vigor e emergência em campo correlacionaram-se entre si, tanto para a variedade BR-IRGA 409 como para a BR-IRGA 410 , devido as condições favoráveis de realização dos testes, que permitiram a expressão do potencial fisiológico das sementes.

As relaçôes entre envelhecimento e emergência nem sempre são consistentes, porque dependem da época de instalação do teste de emergência e do periodo de envelhecimento utilizado. No presente trabalho, a correlação significativa encontrada entre os dois testes, apresentou baixo valor de $r$, tornando o resultado pouco consistente.

\section{CONCLUSÕES}

Com base nos resultados obtidos no presente trabalho de aferição de métodos para determinação da qualidade fisiológica de sementes de arroz, os seguintes aspectos devem ser considerados no uso rotineiro destas avaliações:

a) Os testes de frio modificado e classificação do vigor são capazes de estratificar o vigor de diferentes lotes de sementes de arroz e se correlacionam positivamente com a emergência no campo.

b) $\mathrm{O}$ teste de envelhecimento acelerado pelo método de gerbox, sob as condições de $42^{\circ} \mathrm{C}$ e $100 \%$ de umidade relativa do ar, durante 120 horas, também é capaz de estratificar diferentes lotes de arroz, em função do vigor das sementes.

c) Os testes de tamanho médio e massa seca de plântulas, quando eliminam as plântulas anormais e as sementes não germinadas, não são capazes de estratificar lotes de sementes de arroz, em função do vigor.

\section{REFERÊNCIAS BIBLIOGRÁFICAS}

BARROS, A S. R. Testes para a avaliação rápida da viabilidade e do vigor de sementes de soja (Glycine max $L$. Merril). Piracicaba, 1988. 140p. Dissertação(Mestrado)Escola Superior de Agricultura "Luiz de Queiroz", Universidade de São Paulo.

BRASIL. Ministério da Agricultura e Reforma Agrária. Secretaria Nacional de Defesa Agropecuária. Regras para análise de sementes. Brasília, 1992. 365p.
CARVALHO, N. M. Vigor de sementes. In: CICERO, S. M.; MARCOS FILHO, J.; SILVA, W. R.,( Coord.) Atualização em produção de sementes. Campinas: Fundação Cargill, 1986. p. 207-223.

COSTA, N. P.; PEREIRA, L. A. G.; FRANÇA NETO, J. B.; HENNING,A.A.; KRZYZANOWSKI, F. C.; BARRETO, J. N.; PRADERI, E. V. Padronizaçāo do teste de enveThecimento precoce:resultados de pesquisa de soja 1983/ 84. Londrina: EMBRAPA/CNPSo. 1984.

DAN, E. L.; MELLO, V. D. C.; WETZEL, C. T; POPINIGIS, F.; ZONTA, E. P. Transferência de matéria seca como método de avaliação de vigor de sementes de soja. Revista Brasileira de Sementes, Brasília, v.9, n.3, p.45-55, 1987.

DIAS, M. C. L. L.; BARROS, A. S. R. Aferição de testes de vigor para sementes de feijão. Informativo ABRATES, Londrina, v.3, n.1,p.7-23, 1992.

FRATIN, P. Comparação entre métodos para a avaliação da qualidade fisiológica de sementes de milho (Zea mayz L.). Piracicaba, 1987.191p. Dissertação(Mestrado)- Escola Superior de Agricultura "Luiz de Queiroz", Universidade de São Paulo.

GRABE, D. F. Measurement of seed vigor. Journal of Seed Technology, East Lansing, v.1, n.2, p.18-32, 1976.

ISELY, D. Vigor tests. Proceedings of the Association of Official Seed Analysts, East Lansing, v.4, p.176-182, 1957.

MCDONALD JNIOR, M. B. A review and evaluation of seed vigor tests. Proceedings of the Association of Official Seed Analysts, East Lansing, v.65, p.109139,1975 .

MARCOS FILHO, J.; CICERO, S. M.; SILVA, W. R. Avaliaçāo da qualidade das sementes. Piracicaba: FEALQ, 1987. 230p.

MARCOS FILHO, J.; PESCARIN, H. M. C.; KOMATSU, Y. H.; DEMÉTRIO, C.G. B.; FANCELLI, A. L. Testes para avaliação de vigor de sementes de soja e suas relações com a emergência das plântulas em campo. Pesquisa Agropecuária Brasileira, Brasilia, v.19, n.5, p.605. $613,1984$.

WETZEL, C. T. Contribuição ao estudo da aplicação do teste de envelhecimento visando a avaliação do vigor em sementes de arroz(Oryza sativa L.), de trigo (Triticum aestivum L.) e de soja (Glycine max L. Merril). Piracicaba, 1972. 116p.Dissertação(Mestrado)-Escola Superior de Agricultura "Luiz de Queiroz", Universidade de São Paulo.

Recebido para publicação em 29.08 .94

Aceito para publicação em 18.10 .95 